\title{
Essential Oils as Preservatives in Cosmetics: An Integrative Review
}

\author{
Nicolle Smaniotto Bello ${ }^{1}$, Flavia Tasmin Techera Antunes ${ }^{2}$ and Marcia Gerhardt Martins ${ }^{1 *}$ \\ ${ }^{1}$ Curso de Estética da Universidade Luterana do Brasil, Brasil \\ ${ }^{2}$ Programa de Pós Graduação, Biologia Celular e Molecular Aplicada a Saúde da Universidade Luterana, Brasil
}

\begin{abstract}
Cosmetics are more natural and sustainable due to pressure from the current society, which requires modification in traditional components, usually synthetic. Preservatives, which aim to extend products due to their ability to inhibit the growth and proliferation of microorganisms, are at the forefront of this change. The present study is characterized as an integrative review carried out about the use of essential oils (EO) as a cosmetic preservative, evaluating its effectiveness to replace or complement the current preservative system. The research's guiding question was: EOs are effective as cosmetic preservatives and substitute equivalents for synthetic ones? Twenty-eight articles were selected in the consulted databases (Google Scholar, PubMed, and Scielo). EOs are promising natural preservatives either alone or combined with other EOs and with synthetic preservatives and additives. The results in vitro and cosmetic formulations demonstrated antimicrobial action in a broad spectrum of microorganisms. However, there is no standardization of the methods used to assess the antimicrobial efficacy and few studies with continuity, being necessary to carry out more studies concerning the preservative activity in ready-made cosmetic formulations and in vivo studies with humans using the final product for comparison and, in the future, replacement of synthetic preservatives by the OE.
\end{abstract}

KEYWORDS: Preservative; Essential oil; Cosmetics; Microbiological efficacy

\section{INTRODUCTION}

The cosmetics industry underwent a reformulation, where it began a greener production using resources from the biodiversity of the generating country [1]. This production is due to the population has re-signified the concept of cosmetics, with greater concern about environmental preservation and sustainability, as well as individual well-being and health [2]. Thus, cosmetics are becoming more natural and sustainable and, with this, changes in formulations are being made by components that act in the same way as traditional (usually synthetic).

Any product containing water and organic/inorganic compounds, such as cosmetics, needs an intelligent strategy against microbial contamination [3]. Based on the above, one of the compounds currently discussed is the preservative, which is responsible for the safety of the product to the consumer, so its choice must consider the susceptibility to contamination, physical characteristics-chemical, and possible incompatibilities to avoid changes [4].
Parabens, a class of synthetic preservatives, are the most widely used. Since 1920, its use in the pharmaceutical industry was initiated by its broad spectrum of action, eliminating both fungi and Gram+ bacteria [5]. Currently, methylparaben and ethyl paraben are the most used types in cosmetics because they have good compatibility with formulations, low toxicity, and allergenicity, and low cost; moreover, they are odorless, colorless to white, and active in a wide range of $\mathrm{pH}$ and temperature, being used on the skin, hair, lips, nails, and mucous membranes being their oral and topical use may be uninterrupted [6]. However, due to consumer demands and some studies demonstrating certain risks to human health [7], synthetic chemical preservatives are being set aside by a more natural option. There is a higher demand for natural compounds that can act as a preservative in cosmetics and foods [8]. Because of this, companies are looking for alternative ones with a broad spectrum against pathogens and with a safer feature for consumers [3]. Generally, natural ingredients can also be used in
Quick Response Code:

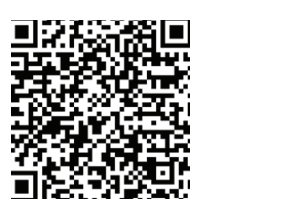

Address for correspondence: Marcia Gerhardt Martins, Avenida Farroupilha, Brasil

Received: December 17, $2021 \quad$ Published: January 31, 2022

How to cite this article: Nicolle SB, Flavia TTA, Marcia GM. Essential Oils as Preservatives in Cosmetics: An Integrative Review. 2022- 4(1) OAJBS.ID.000387. DOI: 10.38125/OAJBS.000387 
cosmetics as functional additives, once their antimicrobial activities are an alternative way to solve the problem of microbial purity of cosmetics [9]. The class of essential oils (EOs) is one of the many natural alternatives for preserving cosmetic products [10]. Thus, this integrative review aimed to evaluate the effectiveness of EOs to replace or complement the current preservative system. In addition, the study reports the main EOs used as preservatives, describing their mechanisms of action and the efficacy tests performed.

\section{METHODS}

This is an integrative review where the guiding question of the research was: Are EOs effective as cosmetic preservatives and substitute equivalents for synthetics? Thus, this study carried out a review in the scientific databases: Google Scholar, Pubmed and
Scielo, being conducted from March to August 2020. The following keywords were used in the search for the articles, with different combinations in Portuguese and English: preservative, cosmetic, essential oil, paraben.

The inclusion criteria defined for the selection of the articles were: scientific articles published with online access, in full text, in Portuguese and English, related to the theme preservative action (antimicrobial, antibacterial, and/or antifungal) in the last twenty years (2000 to 2020). The following exclusion criteria were considered: publications classified as a thesis, letter, dissertations, monographs, manuals, and protocols; and articles that did not address the research question. Figure 1 shows the steps followed in the article selection process.

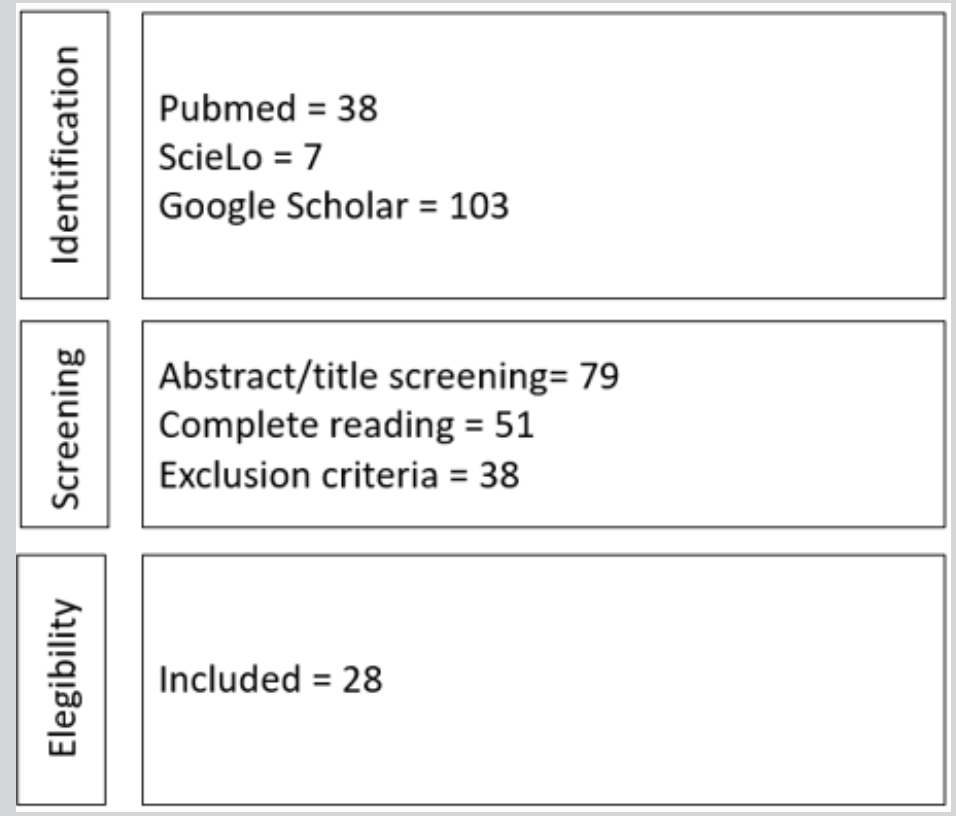

Figure 1: The flowchart in the article selection process.

\section{RESULTS}

The twenty-eight selected articles were segregated and grouped into three categories created according to the subjects addressed in each study, namely: A) scientific articles related to descriptive studies of EOs and its antimicrobial action; B) experimental studies of EOs in cosmetic formulations; D) experimental studies of EOs compared or combined with parabens (Table 1).

Table 1: Characteristics of the studies included in the review.

\begin{tabular}{|c|c|c|}
\hline Authors & Year & Title \\
\hline Juliano et al. [43] & 2000 & $\begin{array}{l}\text { Composition and in vitro Antimicrobial Activity of the Essential Oil of Thymus herba-barona Loisel Growing Wild } \\
\text { in Sardinia }\end{array}$ \\
\hline Cox et al. [18] & 2000 & The mode of antimicrobial action of the essential oil of Melaleuca alternifolia (tea tree oil) \\
\hline Cox et al. [19] & 2001 & Interactions between components of the essential oil of Melaleuca alternifolia \\
\hline Maccioni et al. [29] & 2002 & Preservative systems containing essential oils in cosmetic products \\
\hline Nostro et al. [30] & 2002 & Preservative properties of Calamintha officinalis essential oil with and without EDTA \\
\hline Muyima et al. [28] & 2002 & $\begin{array}{l}\text { The potential application of some novel essential oils as natural cosmetic preservatives in an aqueous cream } \\
\text { formulation }\end{array}$ \\
\hline Nostro et al. [38] & 2004 & Efficiency of Calamintha officinalis essential oil as preservative in two topical product types \\
\hline Pinto et al. [27] & 2006 & Antifungal activity of the essential oil of Thymus pulegioides on Candida, Aspergillus and dermatophyte species \\
\hline Oussalah et al. [45] & 2006 & $\begin{array}{c}\text { Mechanism of Action of Spanish Oregano, Chinese Cinnamon, and Savory Essential Oils against Cell Membranes } \\
\text { and Walls of Escherichia coli 0157:H7 and Listeria monocytogenes }\end{array}$ \\
\hline Gachkar et al. [42] & 2007 & Chemical and biological characteristics of Cuminum cyminum and Rosmarinus officinalis essential oils \\
\hline $\begin{array}{l}\text { Kunicka-Styczyńska et } \\
\text { al. [19] }\end{array}$ & 2009 & Antimicrobial activity of lavender, tea tree and lemon oils in cosmetic preservative systems \\
\hline
\end{tabular}




\begin{tabular}{|c|c|c|}
\hline De Martino et al. [22] & 2009 & $\begin{array}{l}\text { Chemical Composition and Antimicrobial Activity of the Essential Oils from Three Chemotypes of Origanum } \\
\text { vulgare L. ssp. hirtum (Link) Ietswaart Growing Wild in Campania (Southern Italy) }\end{array}$ \\
\hline Patrone et al. [37] & 009 & In vitro synergistic activities of essential oils and surfactantes in combination with cosmetic preservatives against \\
\hline $\begin{array}{l}\text { Kunicka-Styczyńska et } \\
\text { al. [19] }\end{array}$ & 2011 & Lavender, tea tree and lemon oils as antimicrobials in washing liquids and soft body balms \\
\hline Adaszyńska et al. [41] & 2011 & The possibilities or using essential oils as inactive ingredients or preservatives in cosmetic products \\
\hline Bassolé et al. [39] & 2012 & Essential Oils in Combination and Their Antimicrobial Properties \\
\hline Tian et al. [47] & 2012 & The Mechanism of Antifungal Action of Essential Oil from Dill (Anethum graveolens L.) on Aspergillus flavus \\
\hline Wang et al. [23] & 2012 & $\begin{array}{c}\text { Antibacterial Activity and Anticancer Activity of Rosmarinus officinalis L. Essential Oil Compared to That of Its } \\
\text { Main Components }\end{array}$ \\
\hline Yorgancioglu et al. [49] & 2013 & Production of cosmetic purpose collagen containing antimicrobial emulsion with certain essential oils \\
\hline Herman et al. [9] & 2013 & Essential Oils and Herbal Extracts as Antimicrobial Agents in Cosmetic Emulsion \\
\hline Azizkha et al. [21] & 2013 & $\begin{array}{l}\text { Effects of Zataria multiflora Boiss. essential oil on growth and gene expression of enterotoxins A, C and E in } \\
\text { Staphylococcus aureus ATCC } 29213\end{array}$ \\
\hline Dreger et al. [35] & 2013 & Application of essential oils as natural cosmetic preservatives. \\
\hline Herman [20] & 2014 & $\begin{array}{l}\text { Comparison of antimicrobial activity of essential oils, plant extracts and methylparaben in cosmetic emulsions: } 2 \\
\text { months study. }\end{array}$ \\
\hline Chouhan et al. [31] & 2017 & Antimicrobial Activity of Some Essential Oils-Present Status and Future Perspectives \\
\hline Cutillas et al. [25] & 2017 & $\begin{array}{c}\text { Thyme essential oils from Spain: Aromatic profile ascertained by GCeMS, and their antioxidant, antilipoxygenase } \\
\text { and antimicrobial activities }\end{array}$ \\
\hline Hernandes et al. [30] & 2017 & $\begin{array}{l}\text { Lippia origanoides essential oil: an efficient and safe alternative to preserve food, cosmetic and pharmaceutical } \\
\text { products }\end{array}$ \\
\hline Vieira-Brock, et al. [48] & 2017 & $\begin{array}{c}\text { Comparison of antimicrobial activities of natural essential oils and synthetic fragrances against selected } \\
\text { environmental pathogens }\end{array}$ \\
\hline Matos Cruz [8] & 2018 & $\begin{array}{l}\text { Atividade antimicrobiana do óleo de Melaleuca alternifolia comparada a conservantes químicos usados em bases } \\
\text { cosméticas }\end{array}$ \\
\hline
\end{tabular}

\section{DISCUSSION}

\section{Antimicrobial action of EOs}

The first study addressing the antimicrobial activity of EOs probably came from Kabara [11], using plant extracts and EOs as preservative and noting the possibility of replacing synthetic preservatives in cosmetic products. Therefore, this strategy is historically recent, coinciding with the environmental concern and toxicological potential of what we consume in the world [12]. However, approximately in the last 20 years, studies have been stimulated to prove the efficacy of EOs and their active components, mainly by the strong discussion of microbial resistance $[13,14]$ and possible adverse reactions in human health $[7,15]$. This is confirmed in the present results, because there is a growth of studies from 2009 and the years with the highest number of studies were 2013 and 2017.

According to Pereira et al. [16] and Papageorgiou et al. [17], the main EOs used as preservatives are $R$. officinalis, Lavandula officinalis, M. alternifolia, T. vulgaris and S. officinalis. In the current study, it was possible to see that M. alternifolia was the most studied EO among the selected articles, followed by L. officinalis. Most oils had only one study to be analyzed. Most of the articles included analyzed the antimicrobial action of EOs in vitro (13 of 28). E. globulus and M. piperita were the EOs with lower action and lower effectiveness compared to the others, having little action against Staphylococcus aureus and Pseudomonas aeruginosa. S. officinalis was the third with the lowest results, showing little action against S. aureus and Escherichia coli and little or no action against Candida albicans. The others had good results, presenting effective action in at least one microorganism. It can be showed a highlight to $\mathrm{M}$. alternifolia for having action against all the main microorganisms studied and being effective against $S$. aureus, E. coli, C. albicans, and Aspergillus Niger, P. aeruginosa was the most resistant microorganism, but it was observed that even against parabens this microorganism is little affected, being even less effective than L. officinalis, M. alternifolia and C. zeylanicum at $2.5 \%$, according to a study by Herman et al. [9].

The main mechanisms of antimicrobial action of the EOs observed in the articles were rupture of the external membrane or cellular cytoplasmic, leakage of intercellular constituents as ATPase, and inactivation of the mitochondrial activity of microorganisms [8,18-20]. The main ratio of antimicrobial activity can be defined by the active compounds of EOs. The most active EOs had groups of aldehydes, phenols, or terpenes in high concentrations, components such as carvacrol, thymol, terpinen-4-ol, linalool, a-terpineol, and 1,8-cineol found in Z. multiflora [21], O. vulgare [22], M. alternifolia [18], and R. officinalis [23].

However, it is known that thymol, linalool, and carvacrol have broad-spectrum antimicrobial activity [24,25]. Cox et al. [18] compared M. alternifolia and its main active compound, terpinen4-ol, and they observed higher antimicrobial action of terpinen4-ol. In addition, this compound allowed the permeation of other microbicidal components in the cellular cytoplasm. However, it is not only observed in the compounds individually, because in EOs several constituents interact and synergize.

\section{Evaluation of EOs in cosmetic formulations}

The study in cell cultures is an initial analysis and cannot confirm with certainty whether these results will be equal in cosmetic formulations [9]. Because a product has a diverse chemical composition, it can positively or negatively influence the preservative activity of EOs since its action will be the result of synergistic and antagonistic activity of the active components 
[19]. Some ingredients can potentiate or reduce preservative action in cosmetic formulations [26]. This difference in results in vitro and test challenge was observed in the study by Nostro et al. [27] in which the results of $C$. officinalis is an emulsifying ointment (Cetomacrogol) had satisfactory results, however, there were better results when the EO was tested in vitro. With Herman et al. [9] the antimicrobial activities of L. officinalis, M. alternifolia and C. zeylanicum were more effective against microorganisms tested in vitro, and it is believed to be mainly by the interaction of EOs with other chemical components in the emulsion tested.

However, in the study by Muyima et al. [28] the action of Artemisia afra, Pteronia incana, L. officinalis, and R. officinalis were more effective when tested in aqueous cream than in vitro, probably by the interaction with the chelating EDTA in the formulation, contributing to the reduction of cell viability. These interactions with other components in the formulation are also factors observed by Kunicka-Styczyńska et al. [19] with the combination of M. alternifolia, L. officinalis, and C. Limon with the solubilizing polysorbate-80 that increased their activity. Maccioni et al. [29] studying Laurus nobilis, E. globulus and S. officinalis also found an increase in activity against Gram+ bacteria when combined with methyl p-hydroxybenzoate, however different from the others, EOs activities were different when applied in different cosmetic vehicles. While in cream and hydrogel vehicle these EOs had some action in microorganisms, when tested in hydrolysates was not observed reduction or inhibition of microbial growth with none of EOs in 2 weeks. The interference of the chosen vehicle with EOs is also observed with L. origanoids that had antimicrobial action only in aqueous preparations, in the case of shampoo (contained polysorbate 80), although the cream vehicle has BHT (butylated hydroxytoluene) as an antioxidant [30]. These studies suggested that, as synthetic preservatives, EOs need clarification of their possibilities and limitations when applied as a preservative in different cosmetic formulations. Therefore, further evaluations of the effectiveness of EOs are essential.

The characteristic of EOs to be highly volatile raises the question of the possibility of alteration inactivity when exposed to oxygen, light, humidity, or heat, reducing its applicability in the cosmetic, food, and pharmaceutical industries [31]. However, this assumption was not tested in any of the articles, although the authors Matos et al. [8] tested two samples of M. alternifolia collected at different times (June and October), it was concluded that the youngest sample had more activity, however, there was no substantial difference between them. A possibility to reduce the influence of ingredients and limitations by the structure of EOs was seen in one article that did not enter in the review. This work approached the use of thymol, an active compound of several EOs, nano encapsulated in lotions, creams, and aqueous gel to observe if the preservative activity would be more effective. The results demonstrated that the thymol suppressed the growth of E. coli, S. aureus and P. aeruginosa for a longer time than the nonencapsulated one [32]. According to Donsi [33] nanoencapsulation, in food, increases the dispersibility and antimicrobial activity of EOs, being one of the most efficient methods for formulation with bioactive oils. Also, Chouhan et al. [31] reported that encapsulation allows reducing problems of stabilization and effectiveness of EOs in antimicrobial action by releasing in a controlled and sustained way.

\section{Evaluation of EOs combined with other EOs}

The use of EOs as cosmetic preservatives was further studied by the selected articles within a preservative system. This strategy aims to combine more than one ingredient with preservative capacity and/or with potentiating action of the antimicrobial activity of others to make the conservation of the cosmetic product more effective and safer. Preservatives used in cosmetics should have antiseptic power in a wide range of temperature and $\mathrm{pH}$, being effective against various types of microorganisms and not present toxicity and side effects [34]. For EOs to replace synthetic preservatives they must comply with these points. Altogether, being natural does not exclude its toxicological or allergic potential [35]. Regarding toxicity and side effects, no specific article was found, therefore, studies are needed in this aspect. According to Dreger [35], the toxicity of EOs can be classified as low or medium, the majority being considered safe, however, it has the risk of causing irritation, sensitization, phototoxicity, or allergic reactions [36]. Hernandes et al. [30] analyzed the mutagenic potential and acute toxicity of $0.125 \%$ L. origanoids and concluded no mutagenic effects.

A combination of E. globulus and M. piperita increased the action of methylparaben and propylparaben against $P$. aeruginosa [37]. In the same study, the combination of M. piperita, O. vulgare, and $R$ officinalis increased diazolidinyl urea activity against $P$. aeruginosa, $C$. officinalis only affected and reduced the cell viability of $P$. aeruginosa when combined with EDTA in ointment in the study by Nostro et al. [38]. The mixture of L. nobilis and E. Globus or E. globulus and S. officinalis or combined with methylparaben were effective against P. aeruginosa in gel formulation [29]. Besides, $C$. Limon and M. alternifolia were only effective against $P$. aeruginosa when combined with L. officinalis and/or synthetic preservatives [19].

\section{Evaluation of EOs Combined with Paraben}

Only 5 studies comparing EOs with parabens were found $[8,9,20,27,37]$. In comparison with the paraben mixture Fenonip (Methylparaben, Ethylparaben, Propylparaben, Diethylparaben, $0.5 \%$ each), C. officinalis reduced the number of viable microorganisms by $2 \%$. In addition, Matos e Cruz [8] confirmed similar antimicrobial activity among synthetic preservatives, presenting the similarity in the results of $M$. alternifolia against $E$. coli compared to the mixture of Methyl and Propylparaben. Herman et al. [9], noting that the EOs studied were more effective against $S$. aureus, E. coli, and C. albicans than Methylparaben, confirmed that mixing different EOs can effectively inhibit microbial growth across a broad spectrum of activity, it is possible to replace or significantly reduce the number of synthetic preservatives added to cosmetics. Few studies comparing synthetic preservatives with EOs made this discussion promising, but not definitive, and there should be more tests comparing the activity of EOs and traditional preservatives.

Parallel in vitro and in vivo studies have only been seen in one article and cannot be determined whether all EOs are compatible with the chosen preservative system and can ensure the microbiological purity of cosmetics during use and storage. As confirmed by Herman [20], positive results of C. zeylanicum $(2.5 \%)$ in an in vivo study with 40 volunteers for 2 months. This EO completely inhibited bacterial and fungal growth in a cosmetic emulsion, having a better result than the groups that used methylparaben as a preservative. More in vivo studies are expected to confirm the efficacy of EOs as a preservative in finished products and used in clinical practice.

\section{Evaluation of EOs Combined with Other Preservatives}

Regarding efficiency, several studies confirmed the synergistic 
potential of EOs to increase activity of other preservatives. KunickaStyczyńska et al. [19] showed that the synthetic preservative LPG (Glydant Plus Liquid) at $0.1 \%$ in combination with L. officinalis and $M$. alternifolia (each one with $0.5 \%$ ) significantly increased preservative action. M. alternifolia and C. Citrus $1 \%$ combined with $0.2 \%$ LPG increased inhibitory activity of preservatives and, with the same EOs at $0.5 \%$, it occurred inhibition of all microorganisms tested after 2 days and increased fungistatic activity of the synthetic preservative. In 2011, the same authors observed a synergistic effect between M. alternifolia, $L$. officinalis, and C. Limon at $1 \%$. Synergistic action between C. officinalis and EDTA against Grambacteria was seen [27].

Regarding safety, Kunicka-Styczyńska et al. [20], Patrone et al. [37], and Herman et al. [9] cite that the used concentration of synthetic preservatives can be significantly reduced when combined with EOs. This combination allowed to decrease ingredients with allergenic potential in the cosmetic product [35], as seen in the study by Kunicka-Styczyńska et al. [19]. With this, we can see that the combination of EOs with synthetic preservatives, additives, or other EOs increases antimicrobial activity to the point of affecting microorganisms normally resistant to traditional preservatives.

Despite the many positive and promising results of the use of EOs as effective alternative preservatives, many studies have not achieved progress, not allowing greater knowledge of the capacity of certain EOs for the cosmetic industry. This is confirmed by seeing that most EOs found in the present review has only one study. The descriptive articles, mainly, highlight problems such as the diversified evaluation methods, not allowing the comparison of the studies in a completely correct way [31,35,39].

Thus, there is no standardized method developed to evaluate the interaction between EOs [40]. Patrone et al. [37] revealed that there is a need to better understand the possible interactions between preservatives and other ingredients with EOs in formulations to select appropriate cosmetical dosages. Muyima et al. [28] also stated the lack of studies evaluating the efficacy of EOs in specific end products. Also, Matos e Cruz [8] expected the standardization of antimicrobial susceptibility tests specific to EOs to obtain a greater understanding of yield and production cost to clarify the true bioactivity, and with this, the use of EOs as safe and economically viable alternatives for the cosmetic-pharmaceutical market [41-49].

\section{CONCLUSION}

In sum, EOs are promising natural preservatives either isolated or combined with other EOs or synthetic preservatives and additives. Their results in vitro and cosmetic formulations demonstrated antimicrobial action in a broad spectrum of microorganisms. However, there is no standardization of the methods used to evaluate antimicrobial efficacy and few studies with continuity, and it is necessary to perform more experiments concerning preservative activity in ready cosmetic formulations. There is also a lack of comparisons of the action of traditional oils and preservatives and in vivo studies with humans using the final product. EOs can be considered safe to use in a preservative system, reducing the toxicity and concentration of other traditional preservatives, or with other EOs, allowing a broad spectrum of antimicrobial action with natural preservatives.

\section{REFERENCES}

1. Chávez MG (2004) 0 mais profundo da pele: sociedade cosmética na era da biodiversidade. Thesis (Doutorado em Sociologia Política), Faculdade de Sociologia Política, Universidade Federal de Santa Catarina. Florianópolis, Brazil.

2. Rocha JO (2016) Hábitos de consumo de cosméticos naturais na cidade de Porto Alegre. Graduation dissertation. Curso de Administração. Universidade Federal do Rio Grande do Sul. Porto Alegre.

3. Halla N, Fernandes IP, Heleno SA, Costa P, Boucherit-Otmani Z, et al. (2018) Cosmetics preservation: A review on present strategies. Molecules 23(7): 1571.

4. Nowak K, Jabłońska E, Ratajczak-Wrona W (2021) Controversy around parabens: Alternative strategies for preservative use in cosmetics and personal care products. Environ Res 198: 110488.

5. Soni MG, Burdock GA, Taylor SL, Greenberg NA (2001) Safety assessment of propyl paraben: A review of the published literature. Food Chem Toxicol 39(6): 513-532.

6. Vandenberg LN, Bugos J (2021) Assessing the public health implications of the food preservative propylparaben: Has this chemical been safely used for decades. Curr Environ Health Rep 8(1): 54-70.

7. Park J, Lee H, Park K (2021) Gastrointestinal tract and skin permeability of chemicals in consumer products using parallel artificial membrane permeability assay (PAMPA). Environ Anal Health Toxicol 36(3): e2021021-0.

8. Matos JC, Cruz NRS (2018) Atividade antimicrobiana do óleo de Melaleuca alternifolia compared a conservantes químicos usados em bases cosméticas. Revista Remecs, São Paulo 3(4): 21-30.

9. Herman A, Herman AP, Domagalska BW, Młynarczyk A (2013) Essential oils and herbal extracts as antimicrobial agents in cosmetic emulsion. Indian J Microbiol 53(2): 232-237.

10. Sharmeen JB, Mahomoodally M, Zengin G, Maggi F (2021) Essential oils as natural sources of fragrance compounds for cosmetics and cosmeceuticals. Molecules 26(3): 666.

11. Kabara JJ (1984) Aroma preservatives, essential oils and fragrances as antimicrobial agents. Cosmetic and Drug Preservation Principles and Practiceed, CRC Taylor \& Francis, USA.

12. Schimaichel GL, Resende JT V (2006) A importância da certificação de produtos orgânicos no mercado internacional. Revista Eletrônica Lato Sensu 2: 1-16

13. Hectorne KJ, Fransway AF (1994) Diazolidinyl urea: incidence of sensitivity, patterns of cross-reactivity and clinical relevance. Contact Dermatitis 30(1): 16-19.

14. Jong CT, Statham B, Green CM, King CM, Gawkrodger DJ, et al. (2007) Contact sensitivity to preservatives in the UK, 2004-2005: results of multicentre study. Contact Dermatitis 57(3): 165-168.

15. Harvey PW, Everett DJ (2004) Significance of the detection of esters of p-hydroxybenzoic acid (parabens) in human breast tumours. J Appl Toxicol 24(1): 1-4.

16. Pereira CS, Belo RSA, Khouri S, Cardoso MAG (2009) Desenvolvimento de uma formulação farmacêutica utilizando óleo essencial de Melaleuca alternifolia. In: XIII Encontro Latino-Americano de Iniciação Científica e IX Encontro Latino Americano de Pós-Graduação, Universidade do Vale do Paraíba, Brazil.

17. Papageorgiou S, Varvaresou A, Tsirivas E, Demetzos C (2010) New alternatives to cosmetics preservation. J Cosmet Sci 61(2): 107-123.

18. Cox SD, Mann CM, Markham L, Bell HC, Gustafson JE, et al. (2000) The mode of antimicrobial action of the essential oil of Melaleuca alternifolia (tea tree oil). J Appl Microbiol 88(1): 170-175.

19. Kunicka-Styczyńska A, Sikora M, Kalemba D (2011) Lavender, tea tree and lemon oils as antimicrobials in washing liquids and soft body balms. Int J Cosmet Sci 33(1): 53-61.

20. Herman A (2014) Comparison of antimicrobial activity of essential oils, plant extracts and methylparaben in cosmetic emulsions: 2 months study. Indian J Microbiol 54(3): 361-364.

21. Azizkhani M, Misaghi A, Basti AA, Gandomi H, Hosseini H (2013) Effects of Zataria multiflora Boiss. essential oil on growth and gene expression 
of enterotoxins A, C and E in Staphylococcus aureus ATCC 29213. Int Food Microbiol 163(2-3): 159-165.

22. De Martino L, De Feo V, Formisano C, Mignola E, Senatore F (2009) Chemical composition and antimicrobial activity of the essential oils from three chemotypes of Origanum vulgare L. ssp. hirtum (Link) Ietswaart growing wild in Campania (Southern Italy). Molecules 14(8): 2735-2746

23. Wang W, Li N, Luo M, Zu Y, Efferth T (2012) Antibacterial activity and anticancer activity of Rosmarinus officinalis L. essential oil compared to that of its main components. Molecules 17(3): 2704-2713.

24. Oliveira DR, Leitão G, Bizzo HR, Alviano DS, Leitão SG, et al. (2007) Chemical and antimicrobial analyses of essential oil of Lippia origanoides H.B.K. Food Chemistry 101(1): 236-240.

25. Cutillas AB, Carrasco A, Martinez-Gutierrez R, Tomas V, Tudela J (2018) Thyme essential oils from Spain: Aromatic profile ascertained by GC-MS, and their antioxidant, anti-lipoxygenase and antimicrobial activities. J Food Drug Anal 26(2): 529-544.

26. Russell AD (2003) Challenge testing: principles and practice. Int J Cosmet Sci 25(3): 147-153

27. Nostro A, Cannatelli MA, Morelli I, Musolino AD, Scuderi F, et al. (2004) Efficiency of Calamintha officinalis essential oil as preservative in two topical product types. J Appl Microbiol 97(2): 395-401.

28. Muyima NYO, Zulu G, Bhengu T, Popplewell D (2002) The potential application of some novel essential oils as natural cosmetic preservatives in na aqueous cream formulation. Flavour and Flagrance Journal 17(4): 258-266.

29. Maccioni AM, Anchisi C, Sanna A, Sardu C, Dessì S (2002) Preservative systems containing essential oils in cosmetic products. Int J Cosmet Sci 24(1): 53-59.

30. Hernandes C, Pina ES, Taleb-Contini SH, Bertoni BW, Cestari IM, et al. (2017) Lippia origanoides essential oil: an efficient and safe alternative to preserve food, cosmetic and pharmaceutical products. J Appl Microbiol 122(4): 900-910.

31. Chouhan S, Sharma K, Guleria S (2017) Antimicrobial activity of some essential oils-present status and future perspectives. Medicines 4(3): 58

32. Wattanasatcha A, Rengpipat S, Wanichwecharungruang S (2012) Thymol nanospheres as an effective anti-bacterial agent. Int J Pharm 434(1-2): 360-365.

33. Donsi F, Ferrari G (2016) Essential oil nano emulsions as antimicrobial agents in food. J Biotechnol 233: 106-120.

34. Ku J, Han HS, Song JH (2013) The recent trend of the natural preservative used in cosmetics. Korean Journal of Aesthetics and Cosmetology 11(5): 844-935.

35. Dreger M, Wielgus K (2013) Application of essential oils as natural cosmetic preservatives. Herba Polonica 59(4): 142-156.
36. Antignac E, Nohynek GJ, Re T, Clouzeau J, Toutain H (2011) Safety of botanical ingredients in personal care products/cosmetics. Food chem 49(2): 324-341.

37. Patrone V, Campana R, Vittoria E, Baffone W (2010) In vitro synergistic activities of essential oils and surfactants in combination with cosmetic preservatives against Pseudomonas aeruginosa and Staphylococcus aureus. Curr Microbiol 60(4): 237-241.

38. Nostro A, Cannatelli MA, Morelli I, Cioni PL, Bader A, et al. (2002) Preservative properties of Calamintha officinalis essential oil with and without EDTA. Lett Appl Microbiol 35(5): 385-389.

39. Bassolé IH, Juliani HR (2012) Essential oils in combination and their antimicrobial properties. Molecules 17(4): 3989-4006.

40. Tallarida RJ (2001) Drug synergism: Its detection and applications. J Pharmacol Exp Ther 298(3): 865-872.

41. Adaszyńska M, Swarcewicz M (2011) The possibilities of using essential oils as inactive ingredients or preservatives in cosmetic products. Chemistry And Chemical Technology.

42. Gachkar L, Yadegari D, Rezaei MB, Taghizadeh M, Astaneh SA, et al (2007) Chemical and biological characteristics of Cuminum cyminum and Rosmarinus officinalis essential oils. Food Chemistry 102(3): 898904.

43. Juliano C, Mattana A, Usai M (2000) Composition and in vitro antimicrobial activity of the essential oil of thymus herba-barona Loisel growing wild in Sardinia. J Essential Oil Res 12(4): 516-522.

44. Lakeram M, Lockley DJ, Sanders DJ, Pendlington R, Forbes B (2007) Paraben transport and metabolism in the biomimetic artificial membrane permeability assay (BAMPA) and 3-day and 21-day Caco-2 cell systems. J Biomol Screen 12(1): 84-91.

45. Oussalah M, Caillet S, Lacroix M (2006) Mechanism of action of Spanish oregano, Chinese cinnamon, and savory essential oils against cell membranes and walls of Escherichia coli 0157:H7 and Listeria monocytogenes. J Food Prot 69(5): 1046-1055.

46. Pinto E, Pina-Vaz C, Salgueiro L, Gonçalves MJ, Costa-de-Oliveira S, et al. (2006) Antifungal activity of the essential oil of Thymus pulegioides on Candida, Aspergillus and dermatophyte species. J Med Microbiol 55: 1367-1373.

47. Tian J, Ban X, Zeng H, He J, Chen Y, et al. (2012) The mechanism of antifungal action of essential oil from dill (Anethum graveolens L.) on Aspergillus flavus. PloS one 7(1): e30147.

48. Vieira-Brock PL, Vaughan BM, Vollmer DL (2017) Comparison of antimicrobial activities of natural essential oils and synthetic fragrances against selected environmental pathogens. Biochem Open 5: 8-13.

49. Yorgancioglu A, bayramoglu EE (2013) Production of cosmetic purpose collagen containing antimicrobial emulsion with certain essential oils. Industrial Crops and Products 44: 378-382. 